\title{
Modified Current Differencing Unit and its Application for Electronically Reconfigurable Simple First-order Transfer Function
}

\author{
Roman SOTNER ${ }^{1}$, Jan JERABEK ${ }^{2}$, Norbert HERENCSAR ${ }^{2}$, Tomas ZAK ${ }^{1}$, Winai JAIKLA ${ }^{3}$, Kamil VRBA ${ }^{2}$ \\ ${ }^{1}$ Dept. of Radio Electronics, Faculty of Electrical Engineering and Communication, Brno University of \\ Technology, Technicka 3082/12, 61600, Brno, Czech Republic \\ ${ }^{2}$ Dept. of Telecommunications, Faculty of Electrical Engineering and Communication, Brno University of \\ Technology, Technicka 3082/12, 61600, Brno, Czech Republic \\ ${ }^{3}$ Dept.of Engineering Education, Faculty of Industrial Education, King Mongkut's Institute of Technology \\ Ladkrabag, 10520, Bangkok, Thailand \\ sotner@feec.vutbr.cz
}

\begin{abstract}
Modified current differencing unit (MCDU) and its simple filtering application are introduced in this paper. Modification of the well-known current differencing unit consists in weighted difference of both input currents controlled by adjustable current gain, controllable intrinsic resistance of both current input terminals, and availability of additional voltage terminal(s). Definition of MCDU therefore requires four adjustable parameters $\left(B_{1}, B_{2}, R_{\mathrm{p}}, R_{\mathrm{n}}\right)$. A presented active element offers and combines benefits of electronically controllable current conveyor of second generation and current differencing unit and allows synthesis of interesting adjustable applications, which are not available by classical approaches based on simple elements. MCDU brings variability of the transfer function into the structure. It provides several transfer types without necessity of input or output node change by simple electronic tuning. A presented structure represents so-called reconnection-less reconfigurable current-mode filter for realization of all-pass, inverting highpass, low-pass and direct transfer response. Behavioral model of the MCDU was prepared and carefully tested in filtering application. Spice simulations and measurements confirmed theoretical assumptions.
\end{abstract}

Index Terms-Current differencing unit, controllable current gain, controllable intrinsic current input resistance, reconfigurability, multifunctional filter.

\section{INTRODUCTION}

Reconfigurability of the systems is generally a very important requirement of present-day applications (on-chip especially). Microelectronic design of on-chip systems focused on analog parts and signal processing before digitization (A/D conversion) always uses filters, amplifiers, coupling blocks with defined bandwidth, etc. However, chip development is very expensive and, unfortunately, also the results are sometimes inaccurate. Enormous fabrication tolerances cause the main problems with accuracy (deviation of parameters) of analog systems. Therefore, electronically controllable systems based on electronically controllable

Research described in this paper was financed by the National Sustainability Program under grant LO1401 and by the Czech Science Foundation under grant no. GP14-24186P. For the research, infrastructure of the SIX Center was used. Grant No. FEKT-S-14-2281 also supported this research. The support of the project CZ.1.07/2.3.00/20.0007 WICOMT, financed from the operational program Education for competitiveness, is gratefully acknowledged. active elements [1] are really important. We selected active filters as a perfect example of utilization of modern active elements.

\section{A. Classical example of approach to obtain different transfer types in multifunctional filters}

There are multifunctional or universal types of the filters in voltage- (examples [2-6]) and also current-mode (examples [3,4,7-10]) providing low-pass (LP), band-pass (BP), high-pass (HP), band-reject (BR) and all-pass (AP) filtering transfer function simultaneously at several output nodes [2-4] or current output terminals (see [10,11] for example and references cited therein). There are two possibilities of the synthesis of multifunctional multi-loop structures [8-10]. The first approach supposes one input and several outputs (so-called Follow the Leader Feedback state variable structure $[4,10]$ ) or several inputs and one output (so-called modified or inverting Follow the Leader Feedback structure $[4,10])$. The perfect practical example of mutual relation, similarity and difference of both approaches is shown in [12]. Therefore, the types of the filter with one input and several outputs are abbreviated as SIMO (Single Input - Multiple Output) and filters with several inputs and one output are abbreviated MISO (Multiple Input - Single Output). Generally, it does not mean that multi-loop state variable approach was used for their synthesis but it is one of the possible and best known way to obtain tunable multifunctional filtering structures [2-6]. Based on the discussion above, the most important information is that a classical multifunctional filter requires a change of the input or output in structure to obtain different transfer characteristic.

\section{B. Reasons for implementation of reconnection-less multifunctional filtering solutions}

Practical utilization of multifunctional filters in many analog systems is sufficient until a change of transfer function is required and we have no simple way to change input or output physically - in order to introduce galvanic connection (it is a typical problem for on-chip implementation - after fabrication when changes of topology are not possible). We can imagine useful signal, which is to be digitized in $\mathrm{A} / \mathrm{D}$ and some undesirable low- 
or high-frequency components suddenly occur. Now, the signal line with constant frequency response should be changed to HP or LP response and tuned (bandwidth change) in order to remove undesired signals and noises - it is no problem with reconnection of input or output terminals and electronic control of pole frequency in discrete solution of the filter. Required change of the filtering function can be realized also by switches. However, switching of inputs or outputs is not very favorable and brings the additional problems (power consumption and place on PCB or on chip). Additionally, some effects caused by discontinuous regime of operation and mechanical switching are undesired. Chip design requires the best effort to reduce occupied area and additional switches and their control cannot be in compliance with this requirement. We can also set a type of transfer function of the filter directly by controllable parameters of suitable active device. This idea has not been discussed in the literature very often [13-17]. Our paper focuses on filtering solution that allows control of type of the transfer function electronically by parameter(s) of advanced active element.

\section{Brief recapitulation of multi-parameter controllability in known active elements}

Electronic control of parameters in active circuit design came up from first type of rapidly used active devices, operational transconductance amplifier (OTA) [18], where electronic adjusting of the transconductance $\left(g_{\mathrm{m}}\right)$ between input voltage and output current is possible. Discovery of OTA starts the era of amazing development in the circuit applications and active analog signal processing. Active elements with controllable current gain $(B)[19,20]$ and controllable intrinsic resistance of the current input terminal $\left(R_{\mathrm{x}}\right)[21]$ came after short time.

Combination of several controllable parameters in frame of one active device is quite a common way of development of new and improved (from controllability point of view) circuit structures and analog systems in the field of active filters, oscillators, generators, modulators, etc. Minaei et al. [22] proposed the first type of controllable active device that offers $R_{\mathrm{x}}$ and $B$ control. The interesting features of electronic driving are also possible in a proposal published by Kumngern et al. in [23], where translinear current conveyor with similar possibilities has been shown. Marcellis et al. [24] created an active element with voltage and current gain control. Combination of $g_{\mathrm{m}}$ and $R_{\mathrm{x}}$ control can be found many times in literature. Many recently developed active devices combine this way of control, for example several modifications of current differencing transconductance amplifier (CDTA) [1,25], see for example [28-30] and references cited therein. The same method of control was used in modifications of so-called current conveyor transconductance amplifier (CCTA) [1,31], see for example [32].

Despite the fact that a possible way to construct electronically controllable intrinsic resistance of the current input terminal $\left(R_{\mathrm{x}}\right)$ of active element from commercially available devices has been shown quite recently $[33,34]$, many applications were designed with these controllable parameters as a primary mechanism of tuning or adjusting other parameters of filtering transfer function, for example
$[21,30,32]$. However, control of DC bias current in the structure of current conveyor (allowing $R_{\mathrm{x}}$ or $g_{\mathrm{m}}$ control typically) causes undesired influences of output resistance which damages stop band attenuation due to their effect in high-impedance nodes of filtering structure [35]. The development of multi-parameter controllable features of active elements was discussed also in [36] where active element also offers control of $B$ and $R_{\mathrm{x}}$ in frame of special modification of current feedback amplifier (CFA) [1] without impact of $R_{\mathrm{x}}$ control on output resistance [36]. Advanced active element referred to as dual-output controlled-gain voltage-differencing buffered/inverted amplifier (DO-CG-VDBVA) [37] was designed with intention of voltage gain $(A)$ and $g_{\mathrm{m}}$ control. Electronically adjustable voltage and current gain was implemented in socalled controlled-gain buffered current and voltage amplifier (CG-BCVA) [38]. A brief comparison of already known controllable active devices is provided in Table I.

TABLE I. BASIC COMPARISON OF ACTIVE ELEMENTS WITH MULTIPARAMETER CONTROL (IT MEANS MORE THAN ONE)

\begin{tabular}{|c|c|c|c|}
\hline Ref. & $\begin{array}{c}\text { Abbrev. of } \\
\text { active } \\
\text { element }\end{array}$ & $\begin{array}{l}\text { Controllable } \\
\text { parameters }\end{array}$ & $\begin{array}{l}\text { Typical type of } \\
\text { control }\end{array}$ \\
\hline$[22,28-30,32]$ & $\begin{array}{c}\text { ECCII; } \\
\text { CCCDTA; } \\
\text { CCCTA }\end{array}$ & $\overline{R_{\mathrm{x}}, g_{\mathrm{m}}}$ & currents \\
\hline$[23,36]$ & $\begin{array}{c}\text { CCCII; } \\
\text { DCC-CFA }\end{array}$ & $R_{\mathrm{x}}, B$ & currents \\
\hline [37] & $\begin{array}{l}\text { DO-CG- } \\
\text { VDBVA }\end{array}$ & $A, g_{\mathrm{m}}$ & 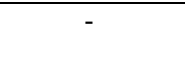 \\
\hline$[24,38]$ & $\begin{array}{l}\text { VGC-CCII; } \\
\text { CG-BCVA }\end{array}$ & $B, A$ & $\begin{array}{c}\text { two DC bias } \\
\text { currents; DC } \\
\text { control } \\
\text { voltages } \\
\end{array}$ \\
\hline proposed & MCDU & two $R_{\mathrm{x}}$, two $B$ & $\begin{array}{c}\text { DC control } \\
\text { voltages }\end{array}$ \\
\hline \multicolumn{4}{|c|}{$\begin{array}{l}\text { Explanations: } \\
\text { ECCII - electronically controllable current conveyor of second } \\
\text { generation } \\
\text { CCCDTA - current-controlled current differencing transconductance } \\
\text { amplifier } \\
\text { CCCCTA - current-controlled current conveyor transconductance } \\
\text { amplifier } \\
\text { CCCII - current-controlled current conveyor of second generation } \\
\text { DCC-CFA - double current-controlled current feedback amplifier } \\
\text { DO-CG-VDBVA - controlled gain voltage-differencing } \\
\text { buffered/inverted amplifier } \\
\text { VGC-CCII - voltage and current gain second generation current } \\
\text { conveyor } \\
\text { CG-BCVA - controlled gain buffered current and voltage } \\
\text { MCDU - modified current differencing unit } \\
A-\text { general controllable voltage gain } \\
B-\text { general controllable current gain } \\
R_{\mathrm{x}}-\text { intrinsic resistance of current input terminal(s) } \\
g_{\mathrm{m}}-\text { transconductance }\end{array}$} \\
\hline
\end{tabular}

The main contribution of this paper is a design of simple first-order reconfigurable filter employing modified version of current differencing unit (CDU) [1,25,27]. Despite the same basic principle (difference of two currents), the modified version of CDU (MCDU) is significantly useful for an application discussed in this paper. The paper is divided as follows: introduction and presentation of MCDU (section 2), reconfigurable filtering solution providing features interesting for practical applications (section 3), proposal of suitable behavioral model of the MCDU and simulation results of the application (section 4), study of important parasitic influences (section 5) and conclusion (section 6). 


\section{MODIFIED CDU}

Basic behavioral model of the CDU, presented by Biolek et al. [1,25-27] as a subpart of the CDTA element, utilizes two current conveyors of second generation (CCII+). Both voltage input terminals are grounded, see Fig. 1. The basic definition of the classic CDU operation is explained by equation: $I_{-\mathrm{x}}=I_{\mathrm{p}}-I_{\mathrm{n}}$. Current differencing buffered amplifier (CDBA) also offers very similar features, for example [1,39]. Classical CDU also does not provide possibility of control of input terminal resistances [21], which is very popular today in advanced types of CDTAs (for example [28-30]). A solution of differential current conveyor (DCC) presented in [40] also allows very similar possibilities (as standard CDTA). Unfortunately, very limited electronically adjustable parameters of the DCC (or its applications) are presented in [40].

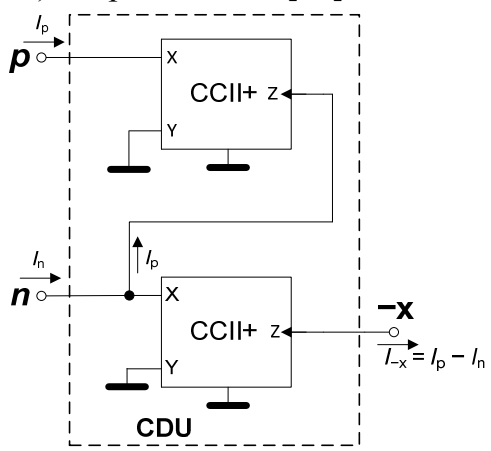

Figure 1. Basic definition of CDU employing two positive current conveyors of second generation

The introduced MCDU also utilizes voltage input terminals Y (two terminals, $Y_{1}$ and $Y_{2}$ are now available, not grounded as in Fig. 1), see Fig. 2. Ideal behavioral model is shown in Fig. 2a. Figure $2 b$ shows a symbol of the MCDU and possible practical utilization based on commercially available active devices is introduced in Fig. 2c. Diamond transistor is used as a simple current inverter. Note that an order of the blocks (ECCII and diamond transistor) can be interchanged in the structure.

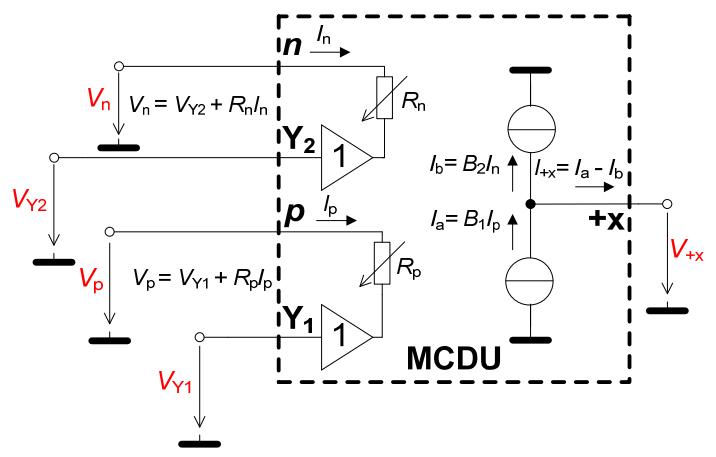

a)
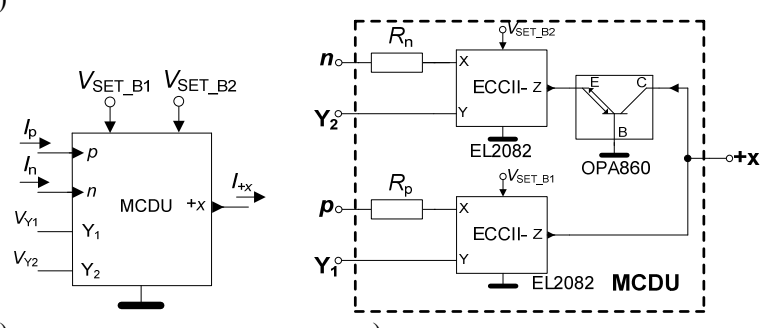

c)

Figure 2. MCDU circuit: a) ideal behavioral model, b) symbol, c) possible practical utilization
MCDU allows independent control of current gain in both current paths as:

$$
I_{+x}=I_{p} B_{1}-I_{n} B_{2},
$$

that brings that interesting features in application which will be introduced later together with controllable input resistances $R_{\mathrm{p}}$ and $R_{\mathrm{n}}$ as is obvious from these relations:

$$
\begin{gathered}
V_{p}=V_{Y 1}+R_{p} I_{p}, \\
V_{n}=V_{Y 2}+R_{n} I_{n} .
\end{gathered}
$$

\section{AppliCATIONS OF MCDU IN ELECTRONICALLY}

\section{RECONFIGURABLE FIRST-ORDER TRANSFER FUNCTION}

The proposed MCDU provides the useful features in simple active filters. Utilization of one or both $\mathrm{Y}$ terminals $\left(\mathrm{Y}_{1}\right.$ and $\left.\mathrm{Y}_{2}\right)$ can bring the interesting features that are not available in applications of basic CDU. The MCDU (Fig. 2) was used in current-mode solution shown in Fig. 3. The additional feedbacks bring opportunity to obtain simple transfer function in a form:

$$
K_{I}(s)=\frac{B_{2}-s C R_{n} B_{1}}{1+s C R_{n}},
$$

Pole and zero frequencies are of the following form:

$$
\omega_{z}=\frac{B_{2}}{C R_{n} B_{1}}, \quad \omega_{p}=\frac{1}{C R_{n}} .
$$

Current-mode filtering solution from Fig. 3 provides the following transfer functions:

a) all-pass (AP) response for $B_{1}=1$ and $B_{2}=1$; zero/pole frequency is controllable by $R_{\mathrm{n}}$ value,

b) inverting high-pass (iHP) response is available for $B_{2}=0$, $B_{1}=1$ (for unity pass-band gain); pole frequency control is possible by $R_{\mathrm{n}}$,

c) low-pass (LP) response for $B_{1}=0, B_{2}=1$; pole frequency controllable by $R_{\mathrm{n}}$,

d) direct transfer (DT) for $B_{1}=-1, B_{2}=1$ and inverting direct transfer (iDT) for $B_{1}=1$ and $B_{2}=-1$.

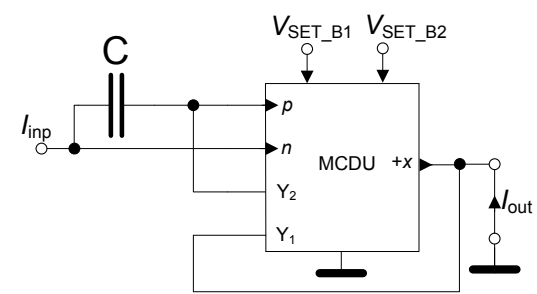

Figure 3. Multifunctional reconfigurable filter utilizing the MCDU circuit

Independent control of zero frequency by $B_{1}$ and $B_{2}$ is possible as is obvious from (5).

\section{Behavioral Model and Simulation Results}

We used structure from Fig. 3 for further analysis. Commercially available devices allow quite easy controllability in applications. Current-mode multiplier EL2082 [41] is very favorable for purposes of behavioral modeling of active elements and applications together with diamond transistors OPA860 [42]. Behavioral model of the MCDU in filtering application (Fig. 3) is shown in Fig. 4. The circuit in Fig. 3 does not require control of $R_{\mathrm{p}}$. Therefore, this element was represented only by fixed passive resistor (its controllability is not necessary in this particular case). Controllable part $R_{\mathrm{n}}$ (dashed red color line) 
was created by sub-block $\left.\left(R_{\mathrm{n}} \cong\left(R_{1}{ }^{\prime}+R_{\mathrm{x} 1}+R_{\mathrm{x} 2}\right) / V_{\text {set_Rn }}\right)\right)$ discussed in detail in [33,34]. All parameters required for control $\left(B_{1}, B_{2}, R_{\mathrm{n}}\right)$ are adjustable electronically by DC voltages $\left(V_{\text {set_B1 }}, V_{\text {set_B2}}, V_{\text {set_Rn }}\right)$.

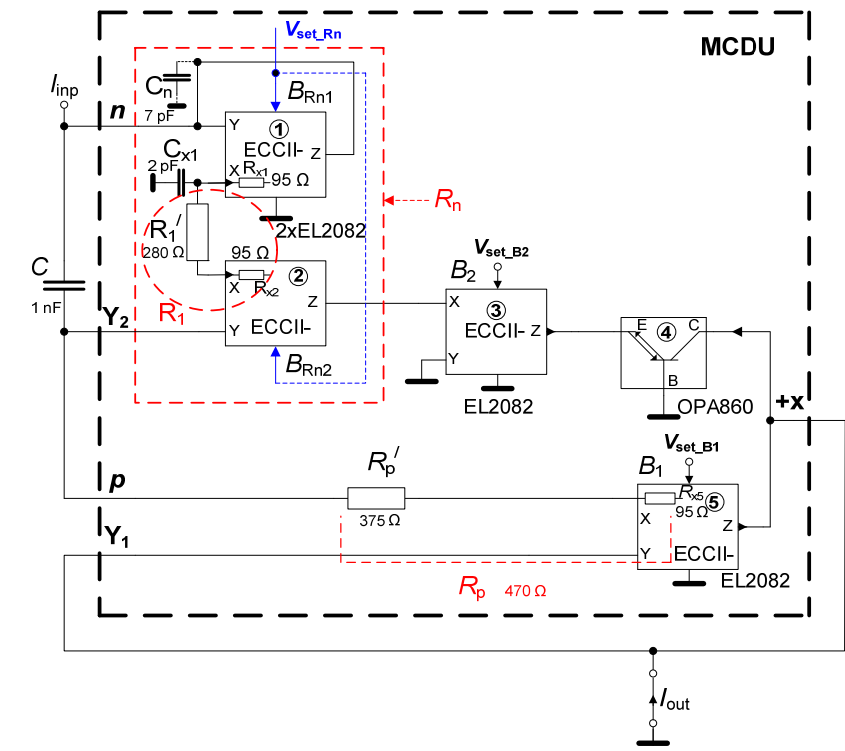

Figure 4. Proposed filter including simplified behavioral model of the MCDU

The values of passive elements are selected as follows: $R_{\mathrm{p}}=470 \Omega$ (including resistance $R_{\mathrm{x} 5}=95 \Omega$ of the terminal $\mathrm{X}$ of the EL2082 [41]), $C=1 \mathrm{nF}$. The $R_{\mathrm{n}}$ control was set and verified in range between $235 \Omega$ and $4.7 \mathrm{k} \Omega$ by $V_{\text {set_Rn }}$ between 2 and $0.1 \mathrm{~V}$. Figure 5 shows the available types of adjustable transfer functions for particular values of $V_{\text {set_B1 }}$ and $V_{\text {set B2 }}\left(B \cong V_{\text {set B }}\right.$ for EL2082 [41]). Ideal pole frequency $\left(f_{\mathrm{pi}}\right) \quad$ is $339 \mathrm{kHz}$ for setting: $V_{\text {set B1 }}=V_{\text {set B2}}=1 \mathrm{~V}$, $V_{\text {set Rn }}=1 \mathrm{~V}(470 \Omega)$. Value $331 \mathrm{kHz}$ was obtained from simulation $\left(f_{\mathrm{ps}}\right)$. Transfers DT and iDT could not be analyzed because this particular behavioral model (Fig. 4) does not allow to set negative gains $(B)$. Tuning of the pole frequency is illustrated in Fig. 6 and Fig. 7. Figure 6 shows adjusting of pole frequency of the AP response and Fig. 7 of the iHP response. The value of resitance $R_{\mathrm{n}}$ was adjusted as: $235 \Omega \quad\left(V_{\text {set Rn }}=2 \quad \mathrm{~V}\right), \quad 470 \Omega \quad\left(V_{\text {set Rn }}=1 \quad \mathrm{~V}\right), \quad 940 \Omega$ $\left(V_{\text {set Rn }}=0.5 \mathrm{~V}\right)$ and $4.7 \mathrm{k} \Omega\left(V_{\text {set Rn }}=0.1 \mathrm{~V}\right)$ in both cases. A range of the pole frequency $\left(\bar{f}_{\mathrm{ps}}\right)$ control from $35 \mathrm{kHz}$ to $623 \mathrm{kHz}$ was obtained, which is very close to ideal values $f_{\mathrm{pi}}=34 \mathrm{kHz}$ to $677 \mathrm{kHz}$. The filter was tested also in time domain in regime of AP function at frequency $339 \mathrm{kHz}$. The results are shown in Fig. 8.

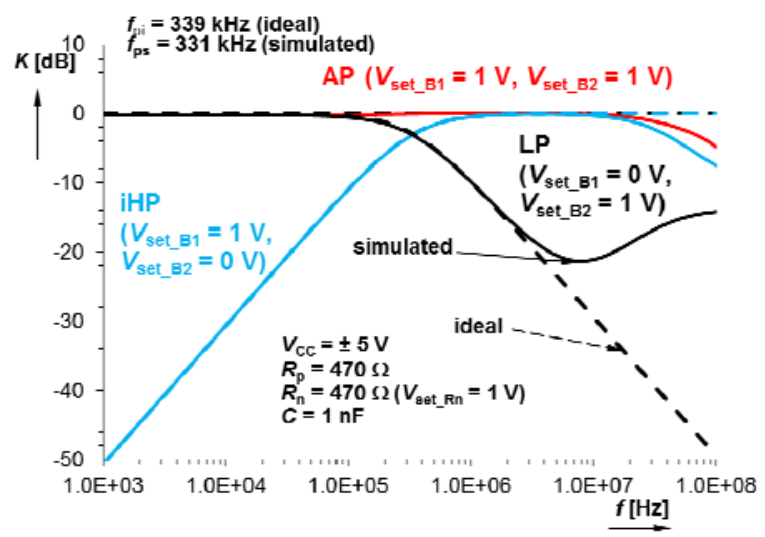

a)

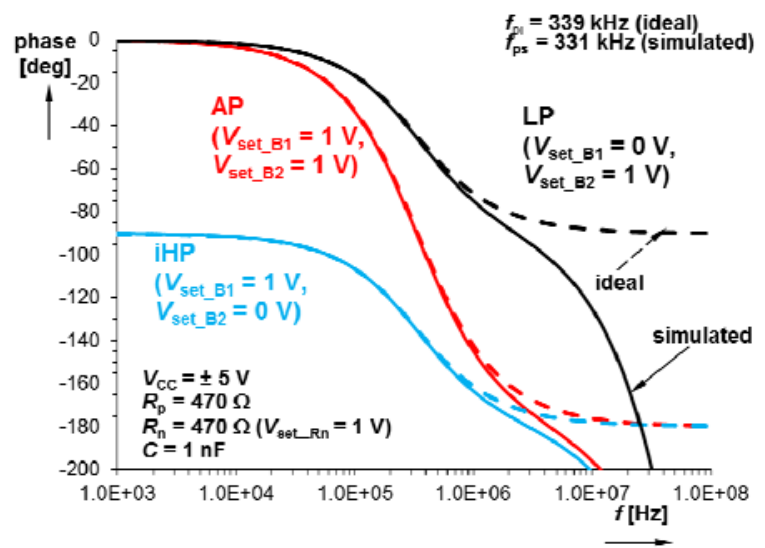

b)

Figure 5. Simulated frequency characteristics of proposed filter in Fig. 4: a) magnitude responses, b) phase responses

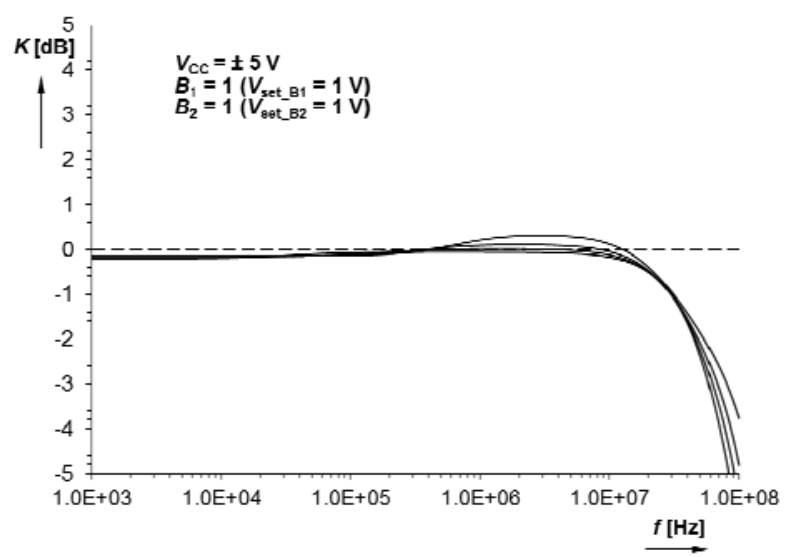

a)

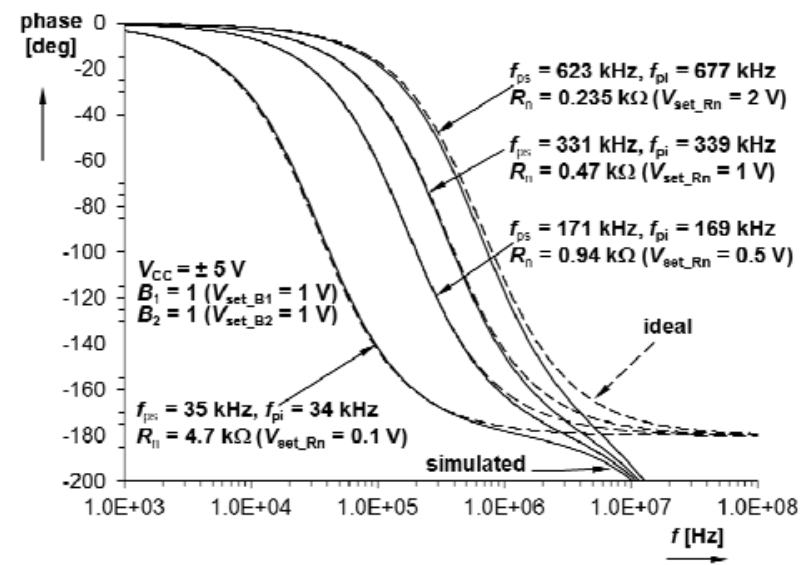

b)

Figure 6. Simulation results in case of tuning of the AP transfer: a) magnitude responses, b) phase responses

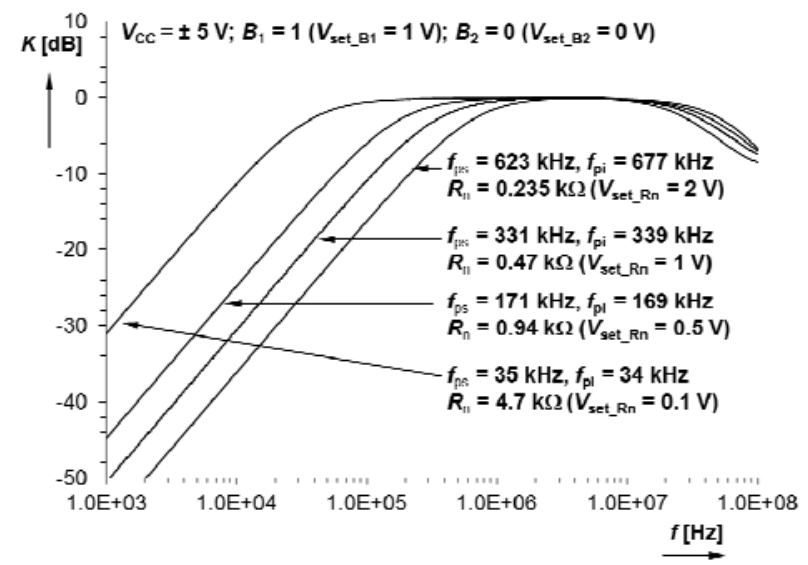

a) 


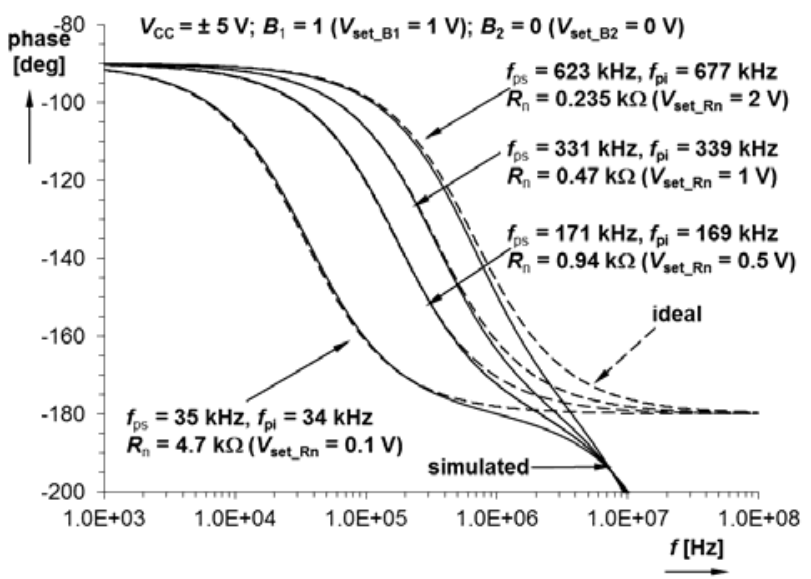

b)

Figure 7. Simulation results in case of tuning of the iHP tranfers: a) magnitude responses, b) phase responses

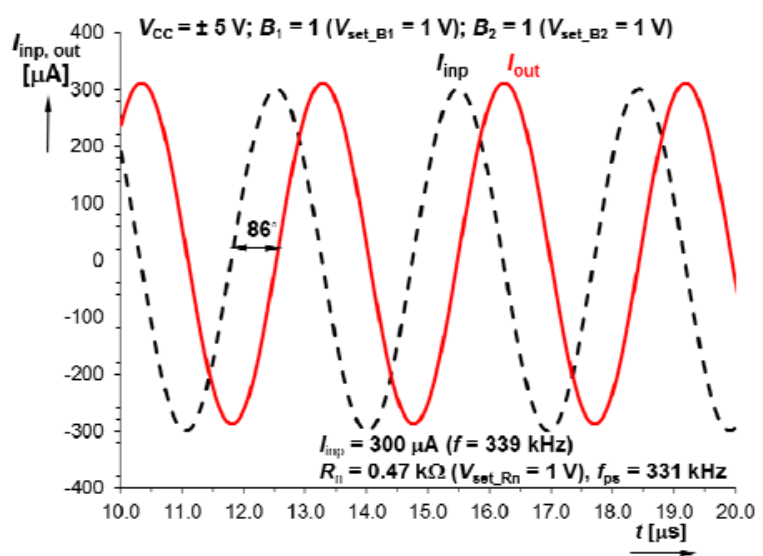

Figure 8. Transient response of the input and output current for AP function (simulation results)

\section{STUDY OF PARASITIC INFLUENCES}

Discussion of parasitic influences is really important. It helps us to understand the real behavior of the circuit. Finite bandwidth of the iHP and AP response at the high frequencies is one of them. This gain drop is not caused by finite frequency features of the used active elements in behavioral model (Fig. 4). The most influencing is parasitic capacitor $C_{\mathrm{n}}$ (see Fig. 4) in the current input terminal $n$. High impedance input and output terminals of the subparts of the behavioral model have sufficiently high values of impedance and their impact in studied bandwidth is not so important, and therefore we can neglect them. Equation (4) is now of the following form:

$$
\begin{aligned}
& K_{I}^{\prime}(s) \cong \frac{B_{2}-s C R_{n} B_{1}}{1+s R_{n}\left(C_{n}+C\right)+s^{2} C C_{p} R_{p}} \\
& =\frac{B_{2}-s C R_{n} B_{1}}{\left(1+s C R_{n}\right)\left(1+s C_{n} R_{p}\right)}
\end{aligned}
$$

We can see an additional pole $\left(\omega_{\mathrm{pp}}=1 / C_{\mathrm{n}} R_{\mathrm{p}}\right)$ that was created by combination of fixed $R_{\mathrm{p}}$ and parasitic $C_{\mathrm{n}}$. Value of $C_{\mathrm{n}}$ is given by capacitances of $\mathrm{Y}$ and $\mathrm{Z}$ terminals of EL2082 $\left(C_{\mathrm{n}} \cong 5-7 \mathrm{pF}\right.$ [41] without additional influences on $\mathrm{PCB}$, etc.). Based on this discussion, expected high frequency gain drop should be obtained between 48 and $68 \mathrm{MHz}$. A simulation result is $68 \mathrm{MHz}$ (for example from Fig. 5, Fig. 6).

Capacitance $C_{\mathrm{n}}$ is given by parasitic features - it cannot be optimized or reduced under minimal limit 5-7 pF if EL2082 is used. Nevertheless, precise PCB design should minimize an additional influences. However, resistance $R_{\mathrm{p}}$ (positive current input terminal) can be adjusted or selected in order to control $\omega_{\mathrm{pp}}$. We can see the impact of $R_{\mathrm{p}}$ value on overall frequency performance in Fig. 9 (observed at AP response).

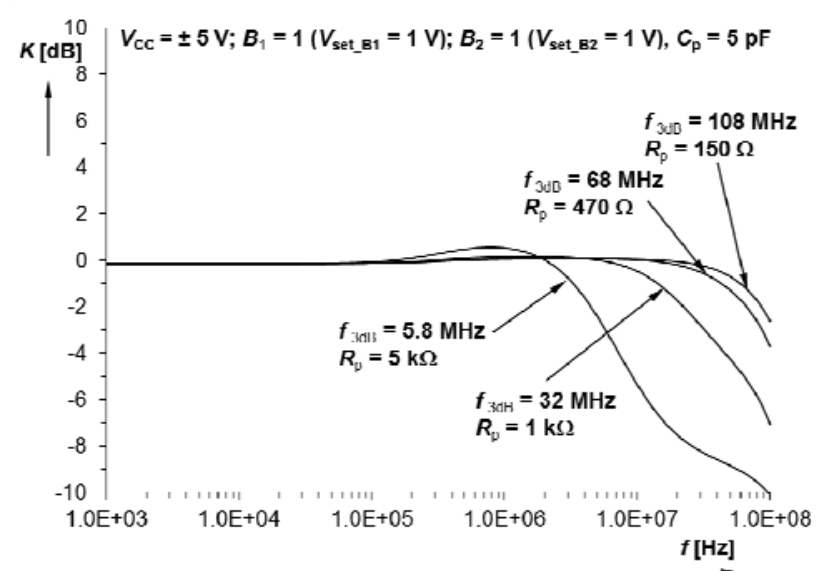

Figure 9. Impact of $R_{\mathrm{p}}$ value on overall frequency performances (AP response)

A problem with parasitic zeros of the LP filter in case of $B_{1}=0$ (Fig. 5) is caused by the used model of controllable $R_{\mathrm{n}}$ (highlighted part in Fig. $4-\mathrm{ECCII}_{1}$ and $\mathrm{ECCII}_{2}$ ). In such case, transfer function (4) in LP configuration $\left(B_{1}=0\right)$ is now of a form (including the main affecting parameters $R_{1}$, $R_{\mathrm{x} 1}$ and $\left.C_{\mathrm{x} 1}\right)$ :

$$
K_{I}^{\prime \prime}(s) \cong \frac{B_{2}\left(1-s^{2} C C_{x 1} R_{x 1} R_{p}\right)}{D^{/ /}(s)},
$$

where

$$
\begin{aligned}
& D^{\prime /}(s) \cong 1+s\left(C_{n} R_{x 1}+C R_{1}+C_{x 1} R_{1}+C R_{x 1}+C_{n} R_{1}\right)+ \\
& +s^{2}\left[C C_{x 1} R_{1}\left(R_{x 1}+R_{p}\right)+C C_{n} R_{p}\left(R_{1}+R_{x 1}\right)+C_{x 1} C_{n} R_{1} R_{x 1}\right]+ \\
& +s^{3} C C_{x 1} C_{n} R_{1} R_{x 1} R_{p}
\end{aligned}
$$

Location of parazitic zero (zeros - two roots symmetrical around y axis) is given by $\omega_{z}= \pm 1 / \sqrt{C C_{x 1} R_{x 1} R_{p}}$. Minimal gain $K_{I}^{\prime \prime}\left(\omega_{z}\right)_{\min }=\lim _{\omega \rightarrow \omega_{z}} K_{I}^{\prime \prime}(s) \quad$ calculated from (8) at zero frequency is approximately $-28 \mathrm{~dB}$. We obtained $f_{\mathrm{z}}=16.8 \mathrm{MHz}$ from (8). It is in quite good correspondence with the results in Fig. 6 . Of course, utilization of other possibilities to control $R_{\mathrm{n}}$ or active devices (ECCIIs) with lower $R_{\mathrm{x}}$ than behavioral model from $[33,34]$ reduces the impact of this problem significantly.

\section{EXPERIMENTAL RESULTS}

We prepared a measurement setup based on ENA E5071C network vector analyzer and two converters employing diamond transistors OPA860 [42]. Established setup is shown in Fig. 10. Device under test (DUT) is based on behavioral model in Fig. 4 with the same values of external passive components. A knowledge of $R_{\mathrm{p}}$ and $R_{\mathrm{n}}$ is critical for estimation of the accurate operation of the MCDU. We measured frequency dependent impedance $Z_{\mathrm{p}}$ and $Z_{\mathrm{n}}$ typical of proposed MCDU (impedance analyzer HP4294A). An example of several traces for selected values of $V_{\text {set_Rn }}\left(V_{\text {set_Rp }}\right)$ is plotted in Fig. 11.

The controllable parameters of the circuit were adjusted 
to confirm expected behavior. However, real values of control voltages are slightly different in comparison with the simulation results. This inaccuracy is given by nonlinear dependence of current gains of the EL2082 [41] on control voltages $V_{\text {set Rn }}, V_{\text {set Rp }}, V_{\text {set B1 }}$ and $V_{\text {set B2 }}$ and its fabrication deviations. Hardly estimable values of parasitic impedances of PCB (additional parasitic capacitances mainly) in highimpedance nodes have also additional and very important impact on accuracy.

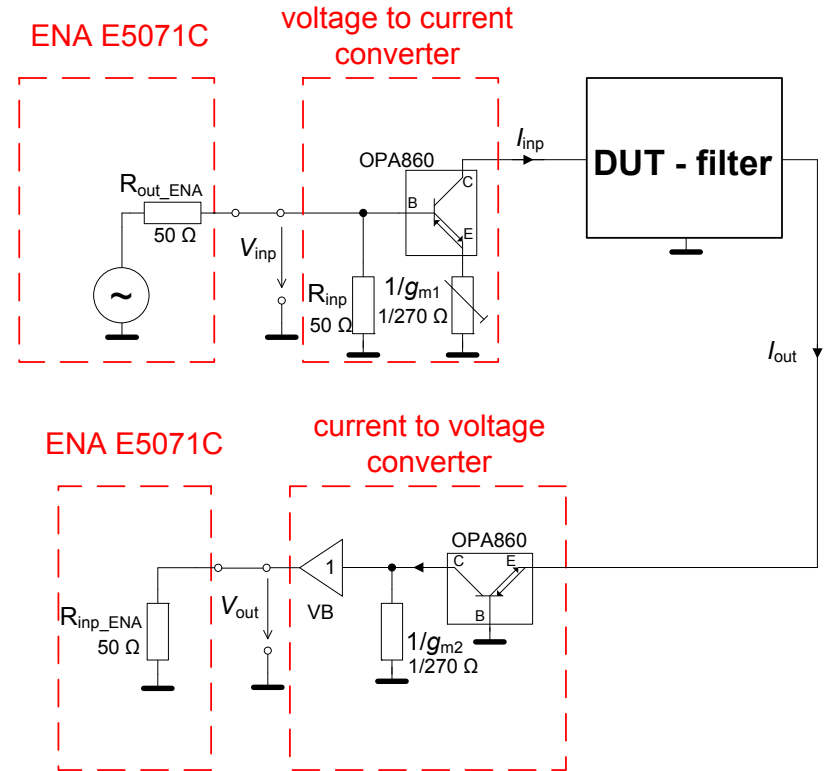

Figure 10. Established measurement setup of the designed filter from Fig. 4

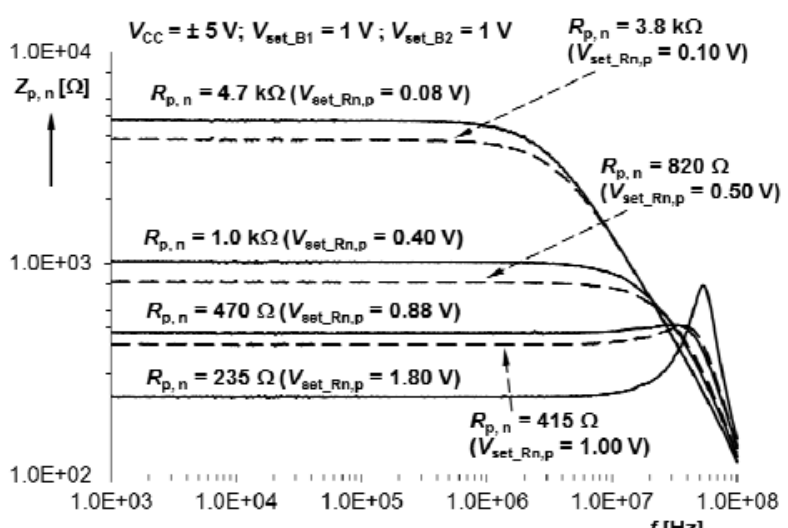

$\stackrel{f[\mathrm{~Hz}]}{\longrightarrow}$

Figure 11. Measured impedances of $n, p$ terminals in dependence on $V_{\text {set_Rp,n }}$

Despite some differences, we can conclude that the experiments confirmed and verified functionality of the reconfigurable filtering structure and we have really emulated behavior of reconfigurable filter based on ideal conception of MCDU device. The results of the experimental tests are given in Fig. 12 - Fig. 14, where magnitude and phase responses of filter in all three basic configurations are shown. Tuning of the filter was verified in case of AP and iHP responses. Frequency characteristics for $V_{\text {set Rn }}$ stepping are given in Fig. 15 and Fig. 16. All constants and parameters of measurements are directly noted in figures.

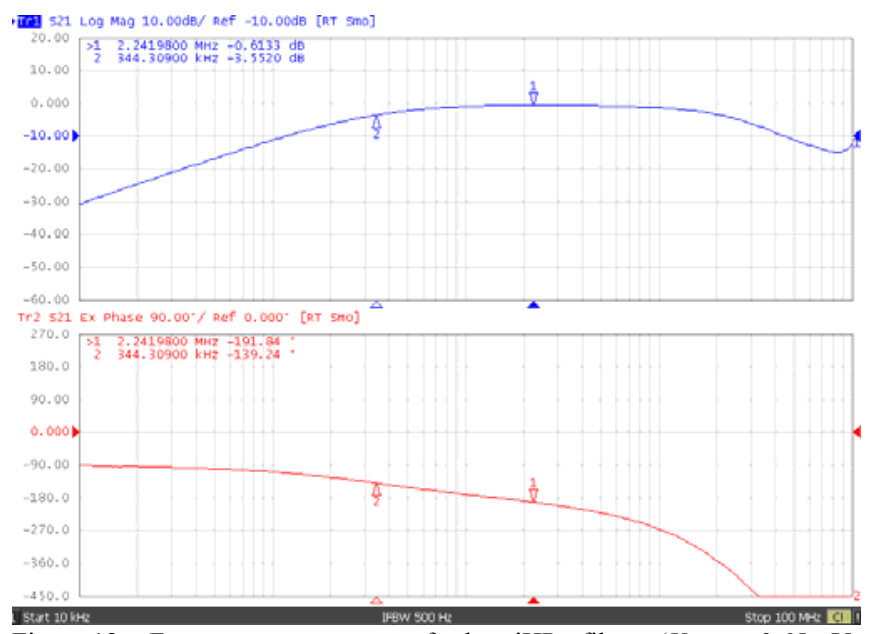

Figure 12. Frequency response of the iHP filter $\left(V_{\text {set_Rn }}=0.65 \mathrm{~V}\right.$, $V_{\text {set_Rp }}=0.89 \mathrm{~V}, V_{\text {set_B1 }}=1.23 \mathrm{~V}, V_{\text {set_B2 }}=0 \mathrm{~V}$ )

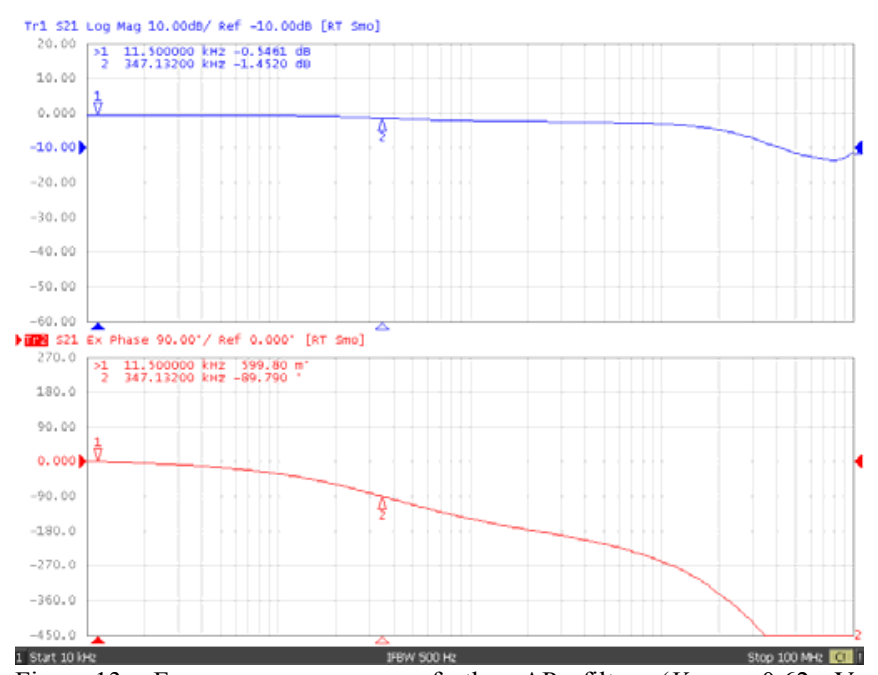

Figure 13. Frequency response of the AP filter $\left(V_{\text {set Rn }}=0.62 \mathrm{~V}\right.$, $V_{\text {set_Rp }}=0.89 \mathrm{~V}, V_{\text {set_B1 }}=1 \mathrm{~V}, V_{\text {set_B2 }}=1 \mathrm{~V}$ )

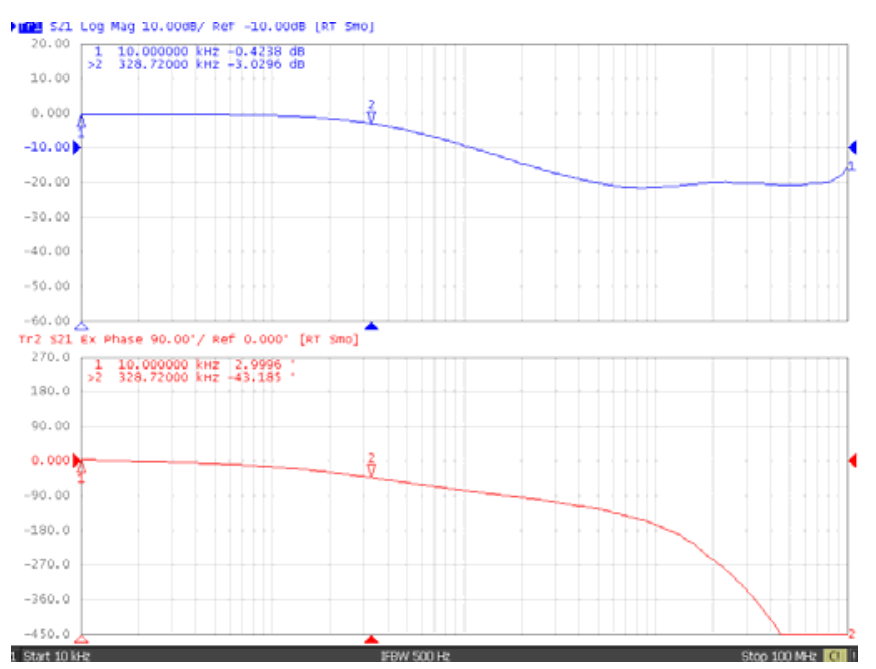

Figure 14. Frequency response of the LP filter $\left(V_{\text {set Rn }}=0.69 \mathrm{~V}\right.$, $\left.V_{\text {set Rp }}=0.89 \mathrm{~V}, V_{\text {set B1 }}=0 \mathrm{~V}, V_{\text {set B2}}=1.1 \mathrm{~V}\right)$ 


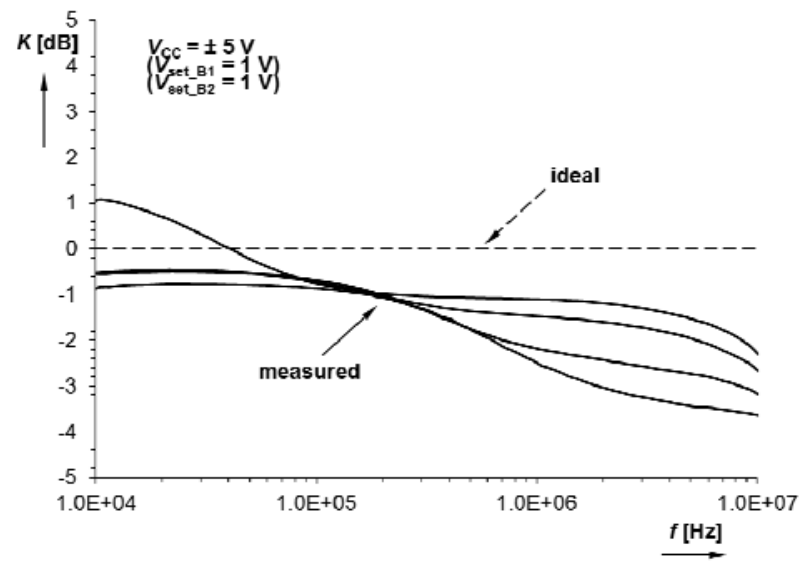

a)

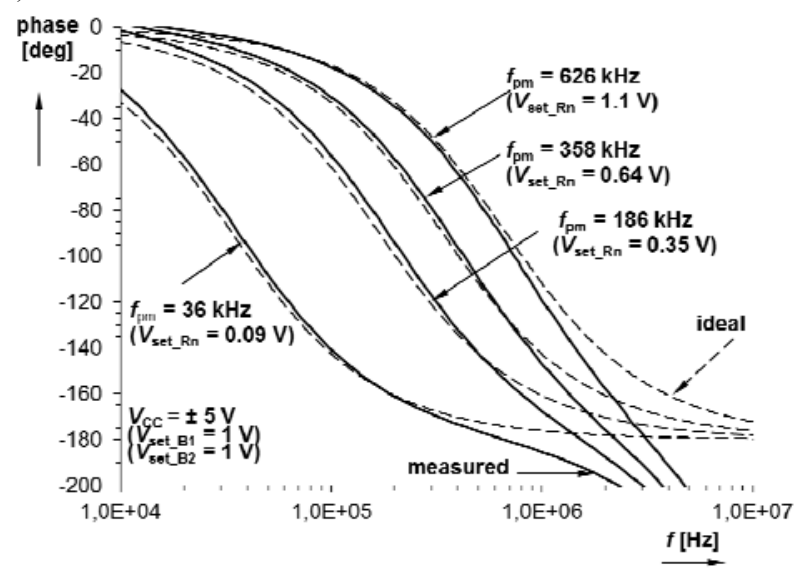

b)

Figure 15. Tuning of the AP filter response by stepping of $V_{\text {set Rn }}$ : a) magnitude responses, $b$ ) phase responses

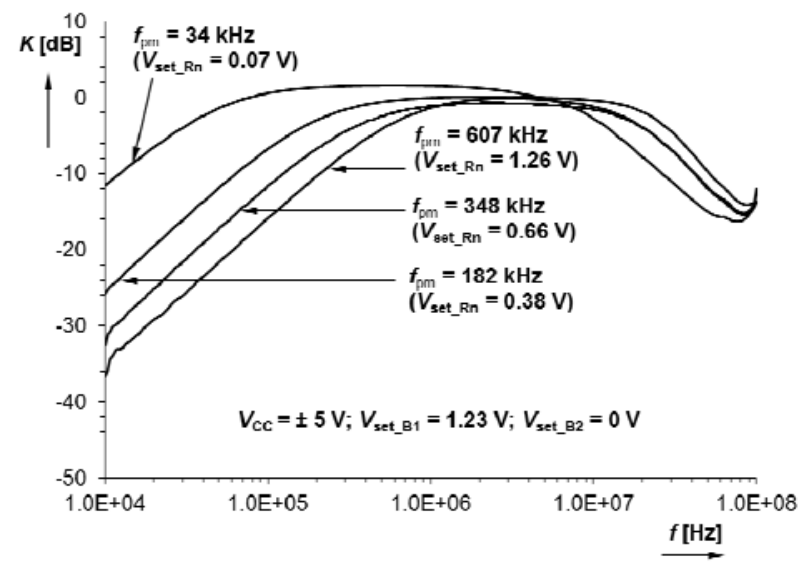

a)

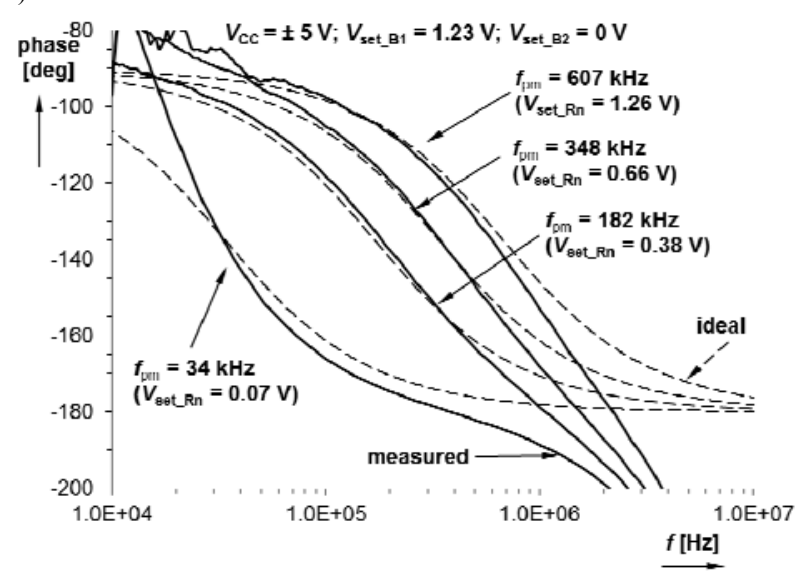

b)

Figure 16. Tuning of the iHP filter response by stepping of $V_{\text {set Rn }}$ : a) magnitude responses, b) phase responses

\section{CONCLUSION}

The definition of the MCDU brings beneficial advantages in comparison with classic simple active elements and basic CDU that does not allow the above discussed controllable features in the filtering applications. The filtering application of the MCDU in Fig. 3 seems to be very interesting because no matching condition for tuning is required and circuit provides all filtering functions that are theoretically available in the first-order filter (namely iHP, LP and AP). Even direct transfer (or inverting direct transfer) is available. Proposed behavioral model of the MCDU allows electronic control of the required parameters $\left(R_{\mathrm{n}}, B_{1}, B_{2}\right)$ in proposed filter (Fig. 4) and operation sustainable up to tens of $\mathrm{MHz}$. Moreover, the proposed structure allows independent pole and zero setting (pole has to be set at first and zero setting does not influence it). Therefore, LP and HP responses with intentional zero (finite attenuation in stop band) are also available from AP response. Simulation and measurement results confirmed theoretical hypotheses and validity of the synthesis.

\section{REFERENCES}

[1] D. Biolek, R. Senani, V. Biolkova, Z. Kolka, "Active elements for analog signal processing: classification, review and new proposals," Radioengineering, vol. 17, no. 4, pp. 15-32, 2008.

[2] J. W. Kerwin, L. P. Hulesman, W. R. Newcomb, "State variable synthesis for insensitive integrated circuit transfer functions," IEEE Journal of Solid State Circuits, vol. 2, no. 3, pp. 87-92, 1967. [Online]. Available: http://dx.doi.org/10.1109/JSSC.1967.1049798

[3] R. Raut, M. N. S. Swamy, Modern Analog Filter Analysis and Design: A practical approach. Weinheim, Germany: Willey-VCH Verlag GmbH and Co. KGaA, 355 p., 2010.

[4] Y. Sun, J. K. Fidler, "Some design methods of OTA-C and CCII-RC filters," in Proc. of IEE Colloquium on Digital and Analogue Filters and Filtering, London, 1993, pp. 7/1-7/8.

[5] R. Nawrocky, U. Klein, "New OTA-capacitor realisation of a universal biquad," Electronics Letters, vol. 22, no. 15, pp. 50-51, 1986. [Online]. Available: http://dx.doi.org/10.1049/el:19860034

[6] Y. Sun, "Second-order OTA-C filters derived from Nawrocky-Klein biquad," Electronics Letters, vol. 34, no. 15, pp. 1449-1450, 1998. [Online]. Available: http://dx.doi.org/10.1049/el:19981036

[7] Y. Sun, J. K. Fidler, "Structure Generation of Current-Mode Two Integrator Dual output-OTA Grounded Capacitor Filters," IEEE Transaction on Circuits and Systems II: Analog and Digital Signal Processing, vol. 43, no. 9, pp. 659-663, 1996. [Online]. Available: http://dx.doi.org/10.1109/82.536762

[8] Y. Sun, J. K. Fidler, "Current-mode OTA-C realization of arbitrary filter characteristics," Electronics Letters, vol. 32, no. 13, pp. 11811182, $1996 . \quad$ [Online]. $\quad$ Available: http://dx.doi.org/10.1049/el:19960807

[9] Y. Sun, J. K. Fidler, "Current-mode multiple-loop feedback filters using dual output OTAs and grounded capacitors," International Journal of Circuit Theory and Applications, vol. 25, no. 2, pp. 69-80, 1997. [Online]. Available: http://dx.doi.org/10.1002/(SICI)1097007X(199703/04)25:2<69::AID-CTA950>3.0.CO;2-9

[10] T. Dostal, "Filters with Multi-Loop Feedback Structure in Current Mode," Radioengineering, vol. 12, no. 3, pp. 6-11, 2003.

[11] R. Sotner, J. Petrzela, J. Slezak, "Current-Controlled Current-Mode Universal Biquad Employing Multi-Output Transconductors," Radioengineering, vol. 18, no. 3, s. 285-294, 2009.

[12] R. Sotner, B. Sevcik, L. Brancik, T. Dostal, "Multifunctional Adjustable Biquadratic Active RC Filters: Design Approach by Modification of Corresponding Signal Flow Graphs," Przeglad Elektrotechniczny, vol. 87, no. 2, pp. 225-229, 2011.

[13] R. Sotner, J. Jerabek, B. Sevcik, T. Dostal, K. Vrba, "Novel Solution of Notch/All- pass Filter with Special Electronic Adjusting of Attenuation in the Stop Band," Elektronika Ir Elektrotechnika, vol. 17, no. 7, p. 37-42, 2011.

[14] J. Petrzela, R. Sotner, "Systematic design procedure towards reconfigurable first-order filters," in Proc. 24th International Conference Radioelektronika 2014, Bratislava, 2014, pp. 237-240. 
[Online].

http://dx.doi.org/10.1109/Radioelek.2014.6828462

Available:

[15] R. Sotner, J. Jerabek, N. Herencsar, R. Prokop, K. Vrba, T. Dostal, "Resistor-less First-Order Filter Design with Electronical Reconfiguration of its Transfer Function," in Proc. 24th Internationa Conference Radioelektronika 2014, 2014, pp. 63-66. [Online]. Available: http://dx.doi.org/10.1109/Radioelek.2014.6828417

[16] R. Sotner, J. Jerabek, J. Petrzela, K. Vrba, T. Dostal, "Design of Fully Adjustable Solution of Band-Reject/All-Pass Filter Transfer Function Using Signal Flow Graph Approach," in Proc. 24th International Conference Radioelektronika 2014, 2014, pp. 67-70. [Online]. Available: http://dx.doi.org/10.1109/Radioelek.2014.6828418

[17] R. Sotner, N. Herencsar, J. Jerabek, R. Prokop, A. Kartci, T. Dostal, K. Vrba, "Z-Copy Controlled-Gain Voltage Differencing Current Conveyor: Advanced Possibilities in Direct Electronic Control of First- Order Filter," Elektronika Ir Elektrotechnika, vol. 20, no. 6, p. 77-83, 2014. [Online]. Available: http://dx.doi.org/10.5755/j01.eee.20.6.7272

[18] S. E. Sanchez, R. L. Geiger, L. H. Nevarez, "Generation of continuous-time two integrator loop OTA filter structures," IEEE Transactions on Circuits and Systems, vol. 35, no. 8, pp. 936-946, 1988. [Online]. Available: http://dx.doi.org/10.1109/31.1840

[19] W. Surakampontorn, W. Thitimajshima, "Integrable electronically tunable current conveyors," IEE Proceedings-G, vol. 135, no. 2, pp. 71-77, 1988

[20] A. Fabre, N. Mimeche, "Class A/AB second-generation current conveyor with controlled current gain," Electronics Letters, vol. 30, no. 16, pp. 1267-1268, 1994. [Online]. Available: http://dx.doi.org/10.1049/el:19940878

[21] A. Fabre, O. Saaid, F. Wiest, C. Boucheron, "High frequency applications based on a new current controlled conveyor," IEEE Trans. on Circuits and Systems - I, vol. 43, no. 2, pp. 82-91, 1996. [Online]. Available: http://dx.doi.org/10.1109/81.486430

[22] S. Minaei, O. K. Sayin, H. Kuntman, "A new CMOS electronically tunable current conveyor and its application to current-mode filters,' IEEE Trans. on Circuits and Systems - I, vol. 53, no. 7, pp. 14481457, $2006 . \quad$ [Online]. Available: http://dx.doi.org/10.1109/TCSI.2006.875184

[23] M. Kumngern, S. Junnapiya, "A sinusoidal oscillator using translinear current conveyors," in Proc. Asia Pacific Conf. on Circuits and Systems APPCAS2010, Kuala Lumpur, 2010, pp. 740-743. [Online]. Available: http://dx.doi.org/10.1109/APCCAS.2010.5774754

[24] A. Marcellis, G. Ferri, N. C. Guerrini, G. Scotti, V. Stornelli, A. Trifiletti, "The VGC-CCII: a novel building block and its application to capacitance multiplication", Analog Integrated Circuits and Signal Processing, vol. 58, no. 1, pp. 55-59, 2009. [Online]. Available: http://dx.doi.org/10.1007/s10470-008-9213-6

[25] J. Vavra, J. Bajer, D. Biolek, V. Biolkova, "Current-mode Quadrature Oscillator Employing ZC-CDU Based All-Pass Filter,” in Proc. IEEE Int. Conf. on Electronics Engineering and Signal Processing (EESP), 2011, Male, pp. 640-644.

[26] J. Vavra, D. Biolek, "OTA-based current differencing unit," in Proc. of int. conf. on Electronic Devices and Systems (EDS IMPAPS), Brno, 2008, pp. 7-12.

[27] W. Jaikla, M. Siripruchyanun, J. Bajer, D. Biolek, "A Simple Currentmode Quadrature Oscillator Using Single CDTA," Radioengineering, vol. 17 , no. 4, pp. 33-40, 2008

[28] W. Jaikla, P. Prommee, "Electronically Tunable Current-mode Multiphase Sinusoidal Oscillator Employing CCCDTA-based Allpass Filters with Only Grounded Passive Elements," Radioengineering, vol. 20, no. 3, pp. 594-599, 2011.

[29] W. Jaikla, A. Lahiri, "Resistor-less current-mode four-phase quadrature oscillator using CCCDTA and grounded capacitors,"
AEU-International Journal of Electronics and Communications, vol. 66, no. 3, pp. 214-218, 2012. [Online]. Available: http://dx.doi.org/10.1016/j.aeue.2011.07.001

[30] M. Siripruchyanun, W. Jaikla, "Electronically Controllable CurrentMode Universal Biquad Filter Using DO-CCCDTA," Circuits Systems and Signal Processing, vol. 27, no. 1, pp. 113-122, 2008 [Online]. Available: http://dx.doi.org/10.1007/s00034-008-9014-2

[31] R. Prokop, V. Musil, "Modular approach to design of modern circuit blocks for current signal processing and new device CCTA," in Proc. Conf. on Signal and Image Processing IASTED, Anaheim, 2005, pp 494-499.

[32] M. Siripruchyanun, W. Jaikla, "Current controlled current conveyor transconductance amplifier (CCCCTA): a building block for analog signal processing”, Electrical Engineering Springer, vol. 90, no. 6, pp. 443-453, 2008. [Online]. Available: http://dx.doi.org/10.1007/s00202-007-0095-x

[33] R. Sotner, J. Jerabek, N. Herencsar, T. Dostal, K. Vrba, "Additional Approach to the Conception of Current Follower and Amplifier with Controllable Features," in Proc. of the 34th Int. Conf. on Telecommunications and Signal Processing (TSP2011), Budapest 2011, pp. 279-283. [Online]. Available: http://dx.doi.org/10.1109/TSP.2011.6043726

[34] R. Sotner, A. Kartci, J, Jerabek, N. Herencsar, T. Dostal, K. Vrba "An Additional Approach to Model Current Followers and Amplifiers with Electronically Controllable Parameters from Commercially Available ICs," Measurement Science Review, vol. 12, no. 6, pp, 255-265, 2012. [Online]. Available: http://dx.doi.org/10.2478/v10048-012-0035-4

[35] J. Jerabek, R. Sotner, K. Vrba, “Tunable universal filter with current follower and transconductance amplifiers and study of parasitic influences," Journal of Electrical Engineering, vol. 62, no. 6, s. 317 326, 2011. [Online]. Available: http://dx.doi.org/10.2478/v10187011-0051-X

[36] R. Sotner, N. Herencsar, J. Jerabek, R. Dvorak, A. Kartci, T. Dostal, K. Vrba, "New double current controlled CFA (DCC-CFA) based voltage-mode oscillator with independent electronic control of oscillation condition and frequency," Journal of Electrical Engineering, vol. 64, no. 2, s. 65-75, 2013. [Online]. Available: http://dx.doi.org/10.2478/jee-2013-0010

[37] R. Sotner, J. Jerabek, N. Herencsar, "Voltage differencing buffered/ inverted amplifiers and their applications for signal generation," Radioengineering, vol. 22, no. 2, pp. 490-504, 2013.

[38] R. Sotner, Z. Hrubos, N. Herensar, J. Jerabek, T. Dostal, "Precise electronically adjustable oscillator suitable for quadrature signa generation employing active elements with current and voltage gain control," Circuits Systems and Signal Processing, vol. 33, no. 1, pp 1-35, 2014. [Online]. Available: http://dx.doi.org/10.1007/s00034 013-9623-2

[39] H. O. Elwan, A. M. Soliman, "CMOS differential current conveyors and applications for analog VLSI," Analog Integrated Circuits and Signal Processing, vol. 11, no. 1, pp. 35-45, 1996.

[40] A. Toker, "Current-mode allpass filters using current differencing buffered amplifier and a new high-Q bandpass filter configuration," IEEE Transactions on Circuits and Systems II, vol. 47, no. 9, pp. 949954, 2000. [Online]. Available: http://dx.doi.org/10.1109/82.868465

[41] Intersil (Elantec). EL2082 CN Current-mode multiplier (datasheet), 1996, 14 p., accessible on ww: http://www.intersil.com/data/fn/fn7152.pdf

[42] Texas Instruments. OPA860 Wide-bandwidth, operational transconductance amplifier (OTA) and buffer (datasheet), 2008, $33 \mathrm{p}$., accessible on www: http://www.ti.com/lit/ds/symlink/opa860.pdf 